\title{
Democracy and cooperation in commons management: experimental evidence of representative and direct democracy from community forests in Ethiopia
}

\author{
TSEGAYE T. GATISO \\ Max Planck Institute for Evolutionary Anthropology, Department of \\ Primatology, Leipzig, Germany. \\ Email: tsegaye_gatiso@eva.mpg.de \\ BJÖRN VOLLAN \\ Philipps-Universität Marburg, School of Business and Economics, Marburg, \\ Am Plan 2, D-35032 Marburg, Germany. \\ Tel: +49-6421 2823725. Fax: +49-64212823780. \\ Email:bjoern.vollan@wiwi.uni-marburg.de
}

Submitted 30 November 2015; revised 23 June 2016; accepted 20 August 2016; first published online 5 December 2016

\begin{abstract}
The authors use dynamic lab-in-the-field common pool resource experiments to investigate the role of two forms of democracy on the cooperation of forest users in Ethiopia. In this experimental setup, participants can either directly select a rule (direct democracy) or elect a leader who decides on the introduction of rules (representative democracy). These two treatments are compared with the imposition of rules and imposition of leaders. It is found that both endogenous leaders elected by the community members and endogenous rules selected by the direct involvement of the participants are more effective in promoting cooperation among the community members compared to exogenous leadership, exogenous rule imposition and the baseline scenario without any of these modifications. However, no significant difference is found between representative democracy in the election of leadership and direct democracy in the selection of rules. Leadership characteristics and behavior are further analyzed. The results underline the importance of democratic procedures.
\end{abstract}

The authors are greatly indebted to DAAD (Deutscher Akademischer Austausch Dienst) for the financial support obtained for this study. They thank Siegfried Bauer, Esther Blanco, Gunnar Brandt, Robert Poppe and Sebastian Prediger for their comments on earlier versions of the paper and Tilahun Ayano for his assistance in the field. 


\section{Introduction}

Since the 1970s many governments in the developing world have started devolving power over the management of resources to local communities. This decision was based on two things - an awareness of the limitations of the top-down approach in the management of natural resources, and an objective to integrate the reduction of rural poverty with natural resource conservation (Charnley and Poe, 2007). However, for community-based conservation approaches to be effective in conserving natural resources, certain conditions need to apply. Communities living in and around natural resources, for example, need to cooperate in rulemaking, and in the monitoring of those rules. Most importantly, for conservation to be achieved, the implemented rules need to be followed by the resource users. For a long time, economists mainly used the rational actor approach to explain rule-breaking behavior. That is, those seeking to maximize personal gains will only engage in non-compliant behavior when the utility of following rules fails to exceed that of delinquent behavior and the perceived cost of sanctions (Becker, 1968). Yet, in many conservation areas, enforcement and probabilities of being monitored are low.

Thus, although rules are non-deterrent, they are nonetheless followed. This suggests that not all behavior is solely motivated explicitly by enforcement or inducement of rules as described by the instrumental model. Norms, which can be seen as non-promulgated prescriptions, can also guide behavior (Posner, 1997). Whether rules become norms may hinge on the legitimacy of rules. Legitimacy means that individuals may normatively assess the reasonability or right of enforcement to regulate their behavior. When actors deem authority to be legitimate and rules to be just, they internalize a sense of obligation to act in a compliant manner (Tyler, 1990; Ramcilovic-Suominen and Epstein, 2012). According to Weber (1968), legitimacy can be gained by tradition, the charisma of the leader or the institutional procedure. In our experimental study we contrast two dimensions of legitimacy: institutional procedure and leadership. We look at the institutional procedure guiding rulemaking, i.e., whether the institutional procedure allows people to vote. When community members have the right to elect, they can either elect a leader who will act on their behalf (representative democracy) or directly elect the management rules (direct democracy). ${ }^{1}$ When the community has no right to elect, there are two possible methods of top-down management. Either the community gets an appointed leader or the community gets rules imposed on them from outside.

Direct democracy gives all the decision power to the people, but it may be less common in real-life governance as it may involve difficulties in reaching agreements and coordination. This form of governance may also be costly both in terms of time and money (Irvin and Stansbury, 2004).

${ }^{1}$ In this paper we use representative democracy for situations in which the local community participates in the election of leaders who in turn choose rules and regulations for their group, whereas direct democracy represents a situation where the community members directly choose the rules through majority vote. 
Representative forms of democracy, on the other hand, give outside organizations (e.g. government or non-governmental organizations or others) a clear representative (or leader) they can talk to, which is more in line with their own hierarchical style of governance, and thus is a preferred form of democratic institution. Yet, the likelihood of having community-oriented leaders who effectively address the needs and aspirations of local communities may hinge on the personality, behavior and performance of the community leaders (Wade, 1994). Some leaders may focus on serving their own personal interests at the expense of their group interests, meaning representative regimes may result in problems of elite capture (e.g. Bardhan, 2002).

There is plenty of evidence on the cooperation-enhancing effects of direct democracy. Pommerehne and Weck-Hannemann (1996) found that in certain Swiss cantons, noncompliance and tax evasion is significantly lower when citizens have direct control over government budgets. Bardhan (2000) found by analyzing 48 irrigation systems in India that farmers who reported the rules had been crafted mostly by the farmers themselves had a positive attitude towards water allocation and were thus more likely to comply with water allocation rules. In addition, a large body of experimental economics literature found that exogenously implemented rules lead to less cooperation among common pool resource (CPR) users compared to rules chosen directly by the affected people through majority vote (Ostrom et al., 1992; Alm et al., 1999; Tyran and Feld, 2006; Dal Bó et al., 2010; Sutter et al., 2010; Markussen et al., 2014; Kamei et al., 2015).

However, there is small but growing evidence that representative democracy is more effective in promoting cooperation compared to appointed (or imposed) leadership. For instance, Luo et al. (2007), using observation data from Chinese villages, reported that the direct election of village leaders leads to higher investment in public goods. Similarly, Grossman (2014), using observational data from farmers' associations in Uganda, found that leaders elected by the direct participation of the members are more responsive to the demands of their members and spur more cooperation compared to leaders appointed by community elites. Baldassarri and Grossman (2011) and Grossman and Baldassarri (2012), using lab-in-thefield experiments in Uganda, also found that groups with elected leaders cooperate more than groups with imposed leaders. In addition, Jack and Recalde (2014) found that contributions for a public good (environmental education books) in rural Bolivia are significantly higher when democratically elected 'real' leaders are assigned to contribute first for the public good compared to randomly assigned leaders.

Nonetheless, evidence from both strands of literature has often been subsumed. One contribution of our study, therefore, is to bridge the gap between studies that independently focus on the role of 'direct democracy' (endogenous rules) and 'representative democracy' (endogenous leadership). We approach the comparison of direct and representative democracy by means of experimental economics methods. We use a set of dynamic lab-in-the-field CPR experiments. These experiments are framed around the extraction of trees from a jointly owned forest, and conducted with local community forest users in rural Ethiopia. Thus, we can further test the 
robustness of the laboratory experiments carried out with students by comparing the findings to a context-laden decision environment and a subject pool of experienced resource users.

Participants in our experiments face a social dilemma like situation. Each participant takes part in two experimental games. In the baseline game (or first game), all groups play the same basic experiment for 10 rounds. In the treatment game (second game), however, participants play the game for another 10 rounds with either one of the two leadership treatments (elected vs. imposed leadership) or with one of the two no-leadership treatments (elected or imposed rules). Thus, we compare representative democracy to direct democracy as well as representative democracy to appointed leadership, and direct democracy to imposed governance. In the first three treatments, either the leader or the group members decide whether to have a predefined sanctioning rule. In the fourth treatment, however, external authorities impose a sanctioning rule. The sanctioning rule is equivalent in all sessions. In sessions with leadership (imposed or elected), the leaders act as 'normal' group members and make their harvest decisions simultaneously with other members.

We find that both direct and representative democracy led to more cooperation than the non-democratic counterparts. However, there is no statistically significant difference between the effect of representative and direct democracy on cooperation. We also find that both appointed and elected leaders reduced their harvest level in the second game. Nonetheless, other members of the groups reduced their harvest level only in sessions with elected leaders. The difference between the effects of the two treatments, therefore, is not due to the behavior of the leaders but due to that of the 'normal' participants.

\section{Related literature}

Our paper relates to several strands of literature and mainly contributes to the growing experimental literature on the effects of leadership on cooperation. There has been a growing interest in using experimental methods to investigate the role of leadership in commons management. Most notably, Rustagi et al. (2010) found that community forests in Ethiopia are regularly monitored and are in better condition if the groups consist of a higher share of conditional cooperators, especially if their democratically elected leader is also a conditional cooperator. ${ }^{2}$ Kosfeld and Rustagi (2015) also found that real-world leaders' decisions to punish varies remarkably and has a strong influence on forest outcomes. Another experiment using real-world leaders compared contributions to a public good (environmental education books) in rural Bolivia when the groups are led by local authorities ('real' community leaders) and randomly assigned leaders (Jack and Recalde, 2014). Jack and Recalde (2014) found that contributions are significantly higher

2 A similar correlation between leaders' behavior and followers' behavior has been found in sequential public goods games with leadership (Levati et al., 2007; Rivas and Sutter, 2011). 
with 'real' leaders. Most experimental studies on leadership, however, use student participants who become leaders within the experiment, who are either randomly assigned or who volunteer to lead. Our study has an intermediate position between the field studies with real leaders - as in Kosfeld and Rustagi (2015) or Jack and Recalde (2014) and lab experiments with students (Güth et al., 2007; Rivas and Sutter, 2008; Sutter et al., 2010; Arbak and Villeval, 2013) - as we implement lab-in-the field experiments with real resource users, but not with real leaders. However, in our study some 'real' leaders take part and become leaders in the experiment if they are chosen by their group members.

Within the experimental literature focusing on the effects of leadership on cooperation, there is growing interest in comparing endogenous vs. exogenous leadership. The two studies most related to ours are Baldassarri and Grossman (2011) and Grossman and Baldassarri (2012). Both studies, using lab-in-the field experiments in Uganda, find that endogenous leadership is more effective in promoting cooperation than imposed leadership. Nonetheless, our experimental design differs in a major way. Leaders in their study neither contribute to the provision of the public good nor benefit from its provision. In their setup, leaders represent a central sanctioning authority that monitors and sanctions group members based on their level of cooperation in the provision of public goods. The leaders' payoff is solely determined by their decision to sanction other members of their group. Conversely, in our study, the role of leaders is to decide whether or not to implement a sanctioning rule on behalf of their groups. Neither monitoring nor sanctioning is the responsibility of the leaders. As is common practice in most co-management regimes, rule enforcement is handed over to the government. We simulate this by randomly picking a card from a basket with participants' ID cards to determine whether a player is monitored and sanctioned. Moreover, in our setup, leaders participate in the extraction of the CPR owned by their group and make their harvest decision simultaneously with other group members. Their payoffs are calculated in a similar fashion to other members of their group. This gives rise to important strategic aspects of leadership. It has been mentioned by various authors of field experimental studies that, during communication sessions, outspoken community leaders who happened to be participants convince other participants to reduce their extraction while themselves extracting even more to reap the highest benefit. While this is anecdotal evidence, a democratically elected leader not enacting sanctions and being aware of his or her effect on the rest of the group may likewise exploit the cooperativeness of the community members.

Furthermore, there is a lack of evidence in the literature on the relative effectiveness of direct democracy and representative democracy in promoting cooperation, particularly in the commons dilemma. Hamman et al. (2011), using lab experiments, found that representative (or delegated, as they call it) democracy leads to more cooperation in the provision of public goods than direct democracy. In their study, participants are given information about the average performance of other members in the baseline game before they choose their leaders. In our study, however, this information was not given. Participants needed to cast their vote in the election for 
a leader based on their collective experience in managing the commons dilemma over (several) years in their real lives. None of the papers we are aware of tests both endogenous vs. exogenous leadership and endogenous vs. exogenous rule implementation. Thus, a major contribution of our study is to have these effects measured in a comparable setup. Also, our experiments with an experienced non-student population serve as a robustness test for the few existing lab studies.

\section{Materials and methods}

\subsection{Participants and study site}

Our study was conducted in six villages of the Chilimo-Gaji community forest located in the Dendi district of the West Shewa zone (in Oromia regional state, Ethiopia). It is roughly $100 \mathrm{~km}$ to the southwest of Ethiopia's capital, Addis Ababa.

The forest cover in the study area has declined dramatically by more than 70 per cent, from over 22,000 ha to 5,800 ha between early 1970 and 2000 (Bekele and Bekele, 2005). As government control proved ineffective, the management of the forest was decentralized and communities living in and around the forest received the right to use and manage the resources communally since the mid-1990s. Resource extraction is limited to collecting dead trees for firewood and controlled harvesting of poles for own-house construction and farm implements. Moreover, the members receive an income from the collective sale of plantation forest. From 2003 to 2012 the natural forest in the study site increased by 7.5 per cent (Kebebew, 2012).

In this paper we report results from a series of experiments with 85 members of community forests in Ethiopia (randomly grouped into 17 sessions with five players each). The participants in our experiment have an average household size of six people and an average education level of 3.32 years. On average the participants were 44 years old. Average livestock possession is 4.85 tropical livestock units (TLU). Most of the participants, 85 per cent, were male. Moreover, the participants were typical community forest users obtaining about 40 per cent of their annual income from their community forest in different forms with firewood being the dominant source. ${ }^{3}$ None of these variables varies significantly across the treatment groups in our experiment, which was mainly assured by the random assignment of participants to the treatments (see table C3 in the online appendix available at https://doi.org/10.1017/S1355770X16000322).

\subsection{Theoretical predictions for the experiment}

We carried out framed field experiments on forest extraction to obtain a context-specific measure of cooperation from members of forest user

${ }^{3}$ Forest income includes earnings related to forest in any form. It includes firewood collection for own consumption or sale, forest-related employment, use of medicinal plants, inputs for crafts making, dividends on shares purchased from forest user groups and others (for details, see Gatiso and Wossen, 2014). 
Table 1. The maximum number of trees allowed for harvest per stock level

\begin{tabular}{cc}
\hline $\begin{array}{c}\text { The number of trees at } \\
\text { the beginning of a round }\end{array}$ & $\begin{array}{c}\text { Maximum number of trees } \\
\text { allowed to harvest }\end{array}$ \\
\hline $51-101$ & 10 \\
$45-50$ & 9 \\
$40-44$ & 8 \\
$35-39$ & 7 \\
$30-34$ & 6 \\
$25-29$ & 5 \\
$20-24$ & 4 \\
$15-19$ & 3 \\
$10-14$ & 2 \\
$5-9$ & 1 \\
$0-4$ & $0-$ game ends \\
\hline
\end{tabular}

groups. The setup of our lab-in-the-field experiment is inspired by a forest harvest game from Cardenas et al. (2013) and Janssen et al. (2013); we modified the game as well as some of the parameters. ${ }^{4}$ Our experiment is designed to represent the situation of a CPR extraction problem commonly known as the commons dilemma (unlike most of the studies in the area that used public goods game) where $n(=5)$ identical individuals make private harvest decisions $\left(x_{i}\right)$ from a commonly owned forest in different rounds $(t)$; subject to the maximum harvest capacity limit of an individual in a specific round $\left(x_{\max }\right)$, i.e., $x_{i t} \in\left[0, x_{\max }\right]$. Harvest decisions are made simultaneously, independently and anonymously. Individuals get a payoff of $k(=E T B 0.5)$ per unit harvested in each round. In addition, all group members receive an equal share of the end stock their group manages to conserve at the end of the game. This share of the end stock is compensation for their conservation effort and it helps to keep optimal harvesting strategies constant over the course of the game. The remaining forest value is shared equally among group members. Since people in the study area are typically underemployed and lack outside employment options (and hence face low opportunity costs), we assume that harvest costs are zero and that there are no alternative investment options.

In our experiment all groups start with an initial stock of 101 trees. The remaining forest at the end of a round re-generates to the next round at the rate of 10 per cent. Furthermore, we assume that the maximum capacity of the forest is equal to the initial stock $\left(A_{0}\right)$, and thus the forest does not grow above the initial stock (i.e. 101 trees). Each participant is allowed to harvest

${ }^{4}$ Modifications made to Cardenas et al.'s (2013) experiment: (a) compensation for the conservation effort in order to get stable predictions of socially optimal forest harvest; (b) increasing the individual maximum allowed from five trees to 10 trees and thereby raising the threshold at which the maximum allowed changes from 25 to 51 trees (see table 1); (c) different experimental treatments in the second game. 
a maximum of 10 trees within a round as long as the stock is greater than or equal to 51 trees. Once the stock drops below 51 trees, the maximum that the participants of that particular group are allowed to harvest is shown in table 1. The maximum amounts of harvest allowed are designed in such a way that the harvest decisions will be non-negative and feasible over the rounds. The game ends after 10 rounds or at any round when there are less than five trees at the beginning of the round.

Based on the parameters chosen for our experiments, we can derive two predictions for extreme behaviors. First, at the one extreme, players are selfish and driven by self-interest maximization motives (i.e., harvest maximum allowed), and secondly, at the other extreme, players are fully cooperative and driven by social welfare maximization motives. ${ }^{5}$ In the first round, a selfish individual appropriates 10 trees, which is the maximum allowed in the first round. Harvesting of 10 trees by each participant results in a total group harvest of 50 trees for the round, leaving only 51 trees on the common plot. After re-growth, in the second round, the groups would have 56 trees on their forest plot. Then, again, selfish individuals harvest 10 trees each in the second round. This leaves only six trees in their forest. Just to recap, we assume that the resource stock needs a minimum level of 10 remaining trees to re-grow. Hence, the forest does not regenerate and the group is left with only six trees to make individual harvest decisions, subject to the maximum limit of one tree each (as defined in table 1) for the next round. The users again realize the maximum harvest of one tree each, which then leads to resource exhaustion after the third round. Since extracting trees yields private benefits worth Ethiopian Birr (ETB) 0.5 per tree harvested, the selfish equilibrium prediction yields individual earning of ETB 10.2 (group earning under this prediction is ETB 51).

The social optimum is obtained with a harvest level that maximizes the group's joint payoff. In the first round, perfectly cooperative groups harvest 10 per cent of the initial endowment, which is equal to the re-growth rate of 10 per cent. Accordingly, individuals harvest two trees each in every round throughout the game and at the end of the game (10th round) manage to conserve more than 89 per cent of the initial stock (for details, see online appendix, table $\mathrm{C} 2$ ). In the social optimum predictions, individuals earn ETB 18 (and group earnings are ETB 90). Note that we pay out the remaining forest at the end of round 10 as compensation for the conservation effort.

\subsection{Experimental treatments}

After the end of the first game, we start a second game for another 10 rounds in which all groups have a new forest of 101 trees. We randomly assigned groups into one of the four treatments: representative democracy, direct democracy, appointed leadership or imposed rule. Random imposition of leaders was done by drawing a card, in front of all participants, from a basket containing five cards labeled with the participants' identification numbers. The election of leaders, however, was carried out by

5 The theoretical details can be found in online appendices A and B. 
secretly writing down the name of a person on a ballot card. Then the leaders decided to implement a sanctioning or no-sanctioning rule, and their groups played the second game with the rule chosen by the leaders. In the direct democracy treatment, participants were given the possibility of voting for or against the proposal to implement a predefined sanctioning rule and in the imposed rule treatment the experimenters randomly assigned a sanctioning or non-sanctioning rule.

In our setup, leaders make harvest decisions simultaneously with other players, and hence there is no possibility to effectively signal additional information. Consequently, leadership does not change the selfish and social optimum. Moreover, the sanctions were intentionally not strong enough to change the selfish predictions of extracting the maximum allowed and social optimum predictions (see online appendix B). Our design reflects the fact that monitoring costs are high for the (local) government and enforcement is difficult, especially in remote areas. Similarly to several interactions in real life related to honesty or cooperation, these 'mild sanctions' are non-deterrent for subjects making individual 'rational' choices based on their own monetary payoffs but they can deter 'norm-abiding' individuals.

In the second game, we informed participants from all groups (including the ones with no leader) to harvest only two trees individually in order to maximize the group gain. Thus, changes between game 1 and game 2 (i.e., the within effect) could be the effect of both information and the treatment (combined effect). However, we can obtain the pure effect of different treatments by comparing sessions with and without leadership in game 2 (i.e., the between-subject effect). Since the between-subject design is considered to be more conservative and thus preferable (Charness et al., 2012), it is crucial that all subjects were informed about the optimal harvest strategy so those not electing the sanction have the same information as those electing the sanction. In groups with leadership, the leaders decide whether to implement a sanction to enforce the restriction of individual harvest to the level that maximizes the group gain (i.e., two trees). In groups with no leadership treatment, either the participants decide to implement the sanctioning rule through majority vote or experimenters randomly assign either the sanctioning or no-sanctioning rule. The sanctioning rule is equivalent in all groups. If someone fails to comply with the regulation (harvesting more than two trees), and is identified as doing so, then twice whatever he/she collected beyond two trees will be deducted from his/her account. We also made clear that subjects are monitored with a one-fifth probability by drawing one player number at the end of each round. Although all members know who was inspected, it was not communicated whether the inspected person was actually sanctioned or not. If a person is not monitored (i.e., his/her card is not observed in the random draw), all the harvested trees will be added to his/her account even if he/she harvests more than two trees in that specific round.

From the 17 groups in our experiment, eight played the second game with leadership and the remaining nine without leadership. While five of the eight groups with leadership were allowed to choose their leader endogenously, in three groups the leaders were randomly imposed. From 
the nine groups without leadership treatments, four groups had the possibility to vote for or against a proposal to implement a sanctioning rule, while in the remaining five groups we randomly assigned sanction or no-sanction (for details, see online appendix, table C1).

At the end of each session, participants were privately paid the cumulated earnings from their own harvest plus their share from the end stock from either the first or second game based on the outcome of a coin toss. Sessions were held in a community building in each location by the same research team. Throughout the games participants were not allowed to communicate with each other. Instructions were read aloud and we illustrated the process by using examples and showing corresponding posters. Three practice rounds were administered (without providing feedback on individual decisions) before the main game started. The experimental protocol is provided in online appendix D.

\section{Results}

To analyze the cooperative behavior of the participants, we use the ratio of individual harvest to the maximum allowed (henceforth harvest ratio $(\mathrm{HR}))$ in each round instead of the absolute harvest level of the subjects. We prefer to use HR to absolute harvest level, as the absolute harvest level of an individual may decline over the rounds simply because of the decline in the stock and the concomitant decline in the maximum allowed harvest even though there is no change in the willingness of a person to cooperate. On the other hand, HR declines only if the individual is willing to harvest less relative to the maximum allowed. Thus, the use of HR is crucial as it makes plausible the comparison of cooperativeness across groups within the same round and/or over rounds for the same group. ${ }^{6}$

\subsection{Descriptive results}

In our experiments, individuals, on average, start the game by realizing 45 per cent of the maximum allowed harvest in the first round of the baseline game. This harvest rate is substantially lower than the first round harvest rate of about 80 per cent reported in Cardenas et al. (2013) and Janssen et al. (2013) for Thailand and Colombia. In our experiment, the HR decreases with rounds played, reaches a minimum in the 6th round and then starts to increase again. The amount of resource, however, declines continuously over time. Participants harvest 25 per cent of their initial stock in the first three rounds, and 50 per cent in the first five rounds. At the end of the game, 13 per cent of the initial stock remains on the common plot (see online appendix, figure C1). Out of 17 groups, only four groups (24 per cent) collapsed prior to round 10, while in Janssen et al. (2013) almost 38 per cent of the groups collapsed prior to the 10th round. We should, however, note that differences between the studies cannot only be attributed to

${ }^{6}$ For interested readers, we report average absolute harvest level of the groups along with the round beginning stock of the group over rounds in online appendix, table C6. 
the availability of the compensation mechanism. First, the compensation mechanism changes the socially optimal harvest behavior. In the studies of Cardenas et al. (2013) and Janssen et al. (2013), it is best for the groups to end with a stock of zero trees. Secondly, we also altered the maximum allowed trees to harvest from five to 10 which leads to different Nash equilibrium predictions (extinction in round 6 in Cardenas vs. round 3 in our experiment). Albeit it is difficult to make direct comparison between our findings and the findings of previous studies, cautious comparison suggests that the compensation for conservation effort might have provided strong incentives for participants to be cooperative and contribute more to the collective action. This can be seen either as suggestive evidence for the importance of payment for ecosystem services (Engel et al., 2008) or for secure property rights that allow communities to optimize over an infinite time horizon instead of a finite time period (Dal Bó, 2005).

To attribute the differences in game 2 to the treatments, it is important to compare behavior of these groups in game 1 before any treatment was in place. As can be seen in the left panel of figure 1, HRs in game 1 had a similar pattern, although their level is higher compared to the level in game 2. Statistical tests show that there is a significant difference (only at 10 per cent significance level) among the four treatments in game 1 (one-way ANOVA with Bonferroni: $d f=84 ; F=2.43 ; p=0.0713$ ), which is mainly due to the difference between the harvest rate of groups with imposed leadership after round 5. This was, in turn, mainly driven by two participants from two groups with imposed leadership who had an HR of 0.75 and 0.72 , while the average HRs of their groups were 0.6 and 0.45 , respectively. To control for potential differences in pro-sociality that may have pre-existed, we: (a) include variables related to harvest behavior in the first game in our regression models in the second game; (b) control for the individual-level sociodemographic variables; (c) check for the robustness of our results by omitting the two least cooperative participants of groups with imposed leadership from our analysis of democracy in the second game; and, most importantly, (d) present results of a within-subject regression which identifies the treatment independent of any potential differences between subjects in game 1 . Our results remain robust to all these modifications.

The relevance of democracy, be it representative or direct, in solving the commons dilemma becomes apparent in the right panel of figure 1 . Democracy significantly promotes cooperation in the commons dilemma. The HR is significantly lower when rules or representatives are established through democratic process compared to imposed institutions $(n=85 ; z=6.119 ; p=0.000)$. Harvest behavior in the second game significantly declines with democratically established procedures (36 per cent) compared to the first game $(n=45 ; z=-4.43 ; p=0.000)$, whereas it increases with imposed institutions (by 28 per cent) compared to the first game $(n=40 ; z=2.85 ; p=0.0044)$.

Result 1. Democratic procedures promote cooperation in the commons dilemma compared to imposed institutions and the baseline game without institutions. 


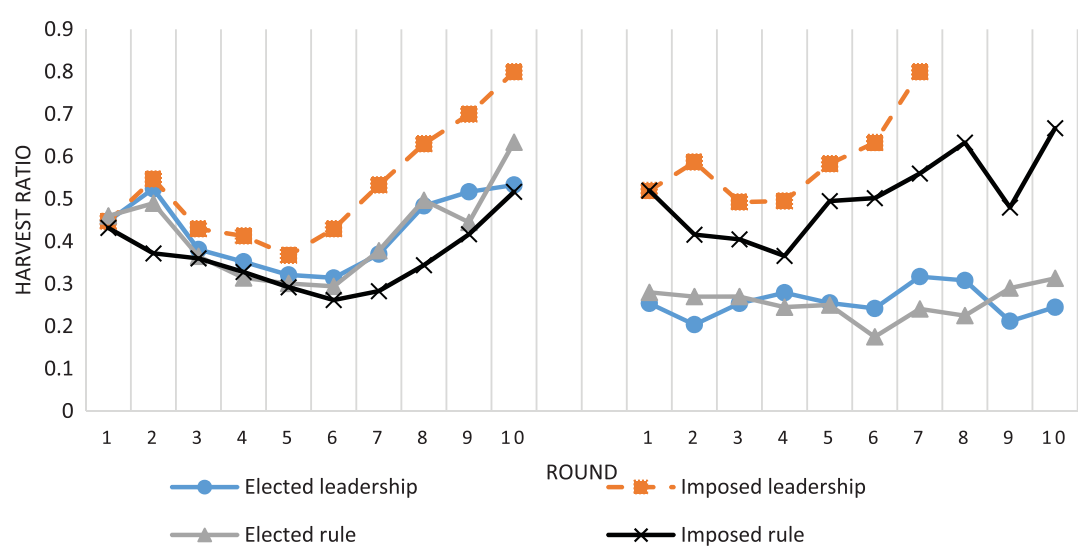

Figure 1. Harvest ratio over rounds separated by treatments

Note: The selfish prediction for the HR is always 1 but the social prediction is 0.2. In the baseline game, after the 5th/6th round, participants are moving towards the selfish prediction.

In the second game, participants from groups with representative democracy, on average, are more cooperative than those from groups with imposed leadership $(n=40, z=4.025, p=0.000)$. The rate of compliance with regulations is also significantly higher for sessions with elected leadership (68 per cent) compared to that for sessions with imposed leadership (45 per cent) $(n=292, z=-3.122, p=0.0018)$. While the average HR of participants in game 2 significantly declines with representative democracy (by 39 per cent) compared to the baseline scenario $(n=25, z=2.892, p=$ 0.0038 ), it increases with the imposed leadership (by 16 per cent), although the increase is not statistically significant $(n=15, z=-1.0794, p=0.2805)$.

Result 2a. Representative democracy promotes cooperation and rule compliance in the commons dilemma compared to imposed leadership and the baseline game without institutions.

In the second game, directly elected rules significantly promote cooperation compared to imposed rules $(n=45, z=4.409, p=0.000)$. Elected rules also significantly promote the rate of compliance with regulations compared to imposed rules $(n=265, z=-2.642, p=0.0023)$. While participants under elected rules comply with regulations in 65 per cent of the cases, participants from sessions with imposed rules comply in only 55 per cent of the cases. Our results also show that, in groups with direct democracy, the HR declines by 38.7 per cent compared to that in the baseline game, which is statistically significant $(n=20, z=-3.435, p=$ 0.0006). Under rule imposition, where rules are randomly assigned, the average $\mathrm{HR}$ in the second game significantly increases relative to that in the baseline game $(n=25, z=2.704, p=0.0068)$.

Result $\mathbf{2 b}$. Direct democracy promotes cooperation and rule compliance compared to imposed institutions and the baseline game without institutions. 
Interestingly, we find no statistically significant difference between the effect of representative democracy and direct democracy on cooperative behavior of the participants $(n=45, z=0.446, p=0.6569)$. Further, there is no significant difference in rule compliance behavior between representative and direct democracy $(n=342, z=0.1196, p=0.9080)$. Both representative democracy and direct democracy treatments perform better than their imposed counterparts and their respective baseline scenarios. Both treatments lead to almost equal percentage reductions in HR. The representative democracy leads to a 39 per cent reduction in HR after its implementation with direct democracy leading to a 38.7 per cent. It is also evident from figure 1 that, on average, the HRs in the second game are lower and more stable over time relative to their respective HRs in the baseline game under both representative and direct democracy. This result may indicate that the positive effect of democracy on cooperation persists over time.

Result 3. There is no significant difference between the effect of direct and representative democracy on cooperation and rule compliance behavior.

Lastly, we find no significant difference in the cooperativeness of groups with imposed rules and imposed leadership $(n=45, z=-1.494, p=$ 0.1992).

We further assess the role of sanctions in promoting cooperation. The availability of sanctions was predominantly chosen by leaders or the group itself (see online appendix, table C1). Only one elected leader and one group in direct democracy did not elect the sanction possibility. In the control group where we randomly decided whether a group would have sanctions or not, we have two groups without sanctions. Maybe surprisingly, these two groups performed more cooperatively than those with imposed sanctions $(n=25, z=-2.275, p=0.0229)$. As can be seen from our regression analysis (table 2), overall neither the availability of sanctions nor the actual sanctions (amount of sanction $(t-1)$ in a given round had significant effects on cooperation levels in the experiment.

Further, there is no significant difference between the harvest behavior of participants from groups with elected leaders who chose to implement a sanctioning rule and those who chose not to implement a sanctioning rule $(n=25, z=1.087, p=0.277)$. Similarly, in the case of direct democracy, no statistically significant difference is found whether a sanctioning rule is established through majority vote or not $(n=20, z=1.092, p=$ 0.2749 ). Combining the two democratic treatments, we also find no statistically significant difference in cooperation whether a sanctioning rule is implemented or not ( $n=45, z=1.584, p=0.1132)$. Moreover, there is no difference in cooperation when a sanctioning rule is chosen by an elected leader (representative democracy) or by direct participation of the group members (direct democracy) $(n=35, z=0.25, p=0.8025)$. Nonetheless, when sanctions are in place, democracy - be it representative $(n=35, z=$ $4.101, p=0.000)$ or direct $(n=30, z=4.281, p=0.000)$ - promotes cooperation significantly compared to imposed sanctions. Moreover, the withinsubjects analysis suggests that, while harvest rates significantly decline in 
Table 2. Random effect Tobit regression: the effect of democracy on HR

\begin{tabular}{|c|c|c|c|c|}
\hline & Model 1 & Model 2 & Model 3 & Model 4 \\
\hline & $\begin{array}{l}\text { Between-subjects } \\
\text { effect of democracy } \\
\text { (game 2) }\end{array}$ & $\begin{array}{l}\text { Between-subjects } \\
\text { effect of amount } \\
\text { of sanction } \\
\text { (game } 2 \text { sessions } \\
\text { with sanction) }\end{array}$ & $\begin{array}{c}\text { Between-subjects } \\
\text { effect of agreeing } \\
\text { with rule or leader } \\
\text { (game } 2 \text { sessions with } \\
\text { election) }\end{array}$ & $\begin{array}{c}\text { Within-subjects } \\
\text { effect of } \\
\text { democracy } \\
\text { (games } 1 \text { and 2) }\end{array}$ \\
\hline Representative democracy ${ }^{a}$ & $\begin{array}{l}-0.345^{* * *} \\
(-6.25)\end{array}$ & $\begin{array}{l}-0.418^{* * *} \\
(-6.29)\end{array}$ & $\begin{array}{l}-0.0989 \\
(-1.46)\end{array}$ & $\begin{array}{l}-0.229^{* * * *} \\
(-5.16)\end{array}$ \\
\hline Direct democracy & $\begin{array}{l}-0.259^{* * *} \\
(-4.36)\end{array}$ & $\begin{array}{l}-0.350^{* * *} \\
(-4.12)\end{array}$ & n.a. & $\begin{array}{l}-0.234^{* * *} \\
(-5.08)\end{array}$ \\
\hline Imposed leadership & $\begin{array}{l}-0.0611 \\
(-0.79)\end{array}$ & $\begin{array}{l}-0.195^{* *} \\
(-2.09)\end{array}$ & n.a. & $\begin{array}{l}0.0988^{*} \\
(1.93)\end{array}$ \\
\hline Imposed rule ${ }^{b}$ & n.a. & n.a. & n.a. & $\begin{array}{l}0.110^{* *} \\
(2.53)\end{array}$ \\
\hline $\begin{array}{l}\text { Agree }(1=\text { agreed, } 0= \\
\text { otherwise })\end{array}$ & n.a. & n.a. & $\begin{array}{l}-0.108^{*} \\
(-1.73)\end{array}$ & n.a. \\
\hline No. votes & n.a. & n.a. & $\begin{array}{l}0.0408 \\
(0.67)\end{array}$ & n.a. \\
\hline $\begin{array}{l}\text { Sanction }(1=\text { sanction, } 0= \\
\text { no-sanction) }\end{array}$ & $\begin{array}{l}0.0952 \\
(1.46)\end{array}$ & & $\begin{array}{l}0.0425 \\
(0.40)\end{array}$ & $\begin{array}{l}0.0128 \\
(0.31)\end{array}$ \\
\hline Amount of sanction $(\mathrm{t}-1)$ & n.a. & $\begin{array}{l}-0.00990 \\
(-1.57)\end{array}$ & & n.a. \\
\hline Round & n.a. & & & $\begin{array}{l}0.00415 \\
(1.21)\end{array}$ \\
\hline First round HR (game 1) & $\begin{array}{l}-0.0449 \\
(-0.51)\end{array}$ & $\begin{array}{l}-0.155 \\
(-1.49)\end{array}$ & $\begin{array}{l}-0.0339 \\
(-0.34)\end{array}$ & $\begin{array}{l}0.275^{* * *} \\
(4.48)\end{array}$ \\
\hline Average HR (game 1) & $\begin{array}{l}0.401^{* *} \\
(2.57)\end{array}$ & $\begin{array}{l}0.530^{* * * *} \\
(2.93)\end{array}$ & $\begin{array}{l}0.606^{* * * *} \\
(4.03)\end{array}$ & \\
\hline $\begin{array}{l}\text { Collapse }(1=\text { Collapsed } \\
\text { before } 10 \text { th round })\end{array}$ & $\begin{array}{l}0.175^{* *} \\
(2.76)\end{array}$ & $\begin{array}{l}0.313^{* * *} \\
(3.74)\end{array}$ & $\begin{array}{l}0.283^{* * *} \\
(2.99)\end{array}$ & \\
\hline End of game ( $1=$ last round $)$ & $\begin{array}{l}0.101^{* *} \\
(2.31)\end{array}$ & $\begin{array}{l}0.0532 \\
(0.92)\end{array}$ & $\begin{array}{l}0.0636 \\
(1.73)\end{array}$ & $\begin{array}{l}0.174^{* * *} \\
(4.64)\end{array}$ \\
\hline Constant & $\begin{array}{l}0.355^{* *} \\
(2.56)\end{array}$ & $\begin{array}{l}0.331^{* *} \\
(2.20)\end{array}$ & $\begin{array}{l}0.0295 \\
(0.07)\end{array}$ & $\begin{array}{c}0.207^{*} \\
(1.80)\end{array}$ \\
\hline $\begin{array}{l}\text { Sociodemographic variables } \\
\text { controlled }^{c}\end{array}$ & Yes & Yes & Yes & Yes \\
\hline Session fixed effect & n.a. & n.a. & n.a. & Yes \\
\hline Round fixed effect & Yes & Yes & Yes & n.a. \\
\hline Left censored observations & 108 & 87 & 85 & 223 \\
\hline Uncensored observation & 585 & 395 & 350 & 1195 \\
\hline Right censored observation & 59 & 51 & 7 & 136 \\
\hline$N$ & 752 & 533 & 442 & 1554 \\
\hline
\end{tabular}

Notes: $z$-statistics in parentheses. ${ }^{*} p<0.05,{ }^{* *} p<0.01,{ }^{* * *} p<0.001$.

${ }^{a}$ For model 3 'Representative democracy' is a dummy that assumes 1 for groups with representative democracy and 0 for direct democracy. ${ }^{b}$ This is a reference category for models 1 and 2, but in model 4 it assumes 1 for sessions with imposed rule and if the game is 2 and it assumes 0 otherwise; ${ }^{c}$ See online appendix, table C6, for regression results with these variables.

groups with elected sanction in the second game compared to the baseline game $(n=35, z=4.242, p=0.000)$, harvest rates increase in groups with imposed sanction in the second game compared to their harvest in the baseline game $(n=30, z=-2.890, p=0.0039)$. Although the availability of sanctions had no overall effect, we found that, when sanctions are implemented, the likelihood of participants complying with regulations is significantly higher if the sanctions are established through democratic 
processes compared to imposed sanctions in both representative ( $n=350$, Spearman's rho $=0.4087, p=0.000)$ and direct democracy $(n=300$; Spearman's rho $=0.3442 ; p=0.001)$. This is in line with DeCaro et al. (2015), who found that enforcing elected rules through sanctions strongly promotes cooperation in the commons dilemma, while imposed sanctions had weak effect on cooperation. Moreover, the authors reveal interesting psychological insights that individuals who voted and had enforcement reported the highest levels of procedural justice and self-determination and because of enforcement, they reported the greatest sense of security. In the case of representative democracy, there was no significant difference between the harvest behavior of those who agreed with the chosen leader and those who have not agreed $(n=25, z=0.741, p=0.4585)$. In the case of direct democracy, however, voting for the implemented rule makes people more cooperative compared to those who have voted against the rule $(n=15, z=2.648, p=0.0081)$.

These results suggest that the most important factor that affects cooperation is the legitimacy of the process rather than the outcome of the process (i.e. whether a sanction was chosen or not). Furthermore, we found that people also tend to follow recommendations even if they are not enforced by sanctions once the process involves democracy.

Result 4. Leaders or groups who chose a sanctioning regime did not outperform those groups who chose not to have sanctioning regimes.

\subsection{Estimation of treatment effects including the effect of sanctions}

To account for other factors that may affect the results above, we apply two distinct econometric models. ${ }^{7}$ First, we estimate the between-subjects effect of democracy in the election of leadership and rule formation (only game 2). In this model we include three dummy variables in the regression: 'Representative democracy' (1 if elected leadership, 0 otherwise), 'Direct democracy' ( 1 if the rule is chosen by majority vote; 0 otherwise), 'Imposed leadership' ( 1 if randomly imposed leadership; 0 otherwise), while the reference category is 'Imposed rule' where the rules are randomly assigned by the experimenter. In the regression models we also include the first round $\mathrm{HR}$, average HR from the baseline game and whether the resource has collapsed before the 10th round in the baseline game. The first round HR in game 1 accounts for the effect of unconditional cooperation. The average harvest behavior and the resource collapse accounts for differences in game 1, which may be due to learning and reciprocal behavior. Including these variables controls for ex ante differences in pro-sociality which may arise in small samples and for differential learning effects that may carry

${ }^{7}$ Albeit we base our discussion on the random effects Tobit model, we report the results from other models (such as GLS) in online appendix, table C8, for robustness of the results. Our basic model is a random effects regression model, as we are interested in the effect of both time-variant and time-invariant explanatory variables on the dependent variable (i.e., HR). Moreover, we use the Tobit model as our main model since the dependent variable (HR) is censored from both the bottom and top and has non-negligible corner solutions. 
over to the second game. Of course this is not a fully satisfactory solution for a between-subject design. Therefore, we also estimate a within-subject design which controls for individual differences that remain constant over time.

In table 2, model 1, representative democracy significantly improves cooperation as compared to the reference category where the rules are directly imposed by external authorities. We find that representative democracy has a positive and statistically significant effect on cooperation in the commons dilemma compared to the reference category. Direct democracy also influences cooperation positively and significantly. Participants cooperate more under direct democracy than imposed rules. However, the HR (and cooperative behavior) of the participants that play the game with an imposed leader is not significantly different from those who played the game with imposed rules. The results also reveal that the average harvest behavior in the baseline game positively and significantly affects the harvest behavior in the second game, suggesting some persistence of behavior over the two games. The harvest behavior at the beginning of the baseline game (unconditional cooperation) has an insignificant effect on average harvest rate over the baseline game. Sociodemographic and perception variables seem to have no effect on the harvest behavior in the second game (see online appendix, table C6, for regression results including these variables). Our results are robust to different regression models. For example, random effect Tobit regressions excluding sociodemographic and perception variables yield similar results. Moreover, regression results from random effects GLS models with standard errors clustered at the group and individual level also produce similar results (see online appendix, table $\mathrm{C} 8$ ). In model 2 , we include the amount of sanctions in the previous round $(t-1) \cdot{ }^{8}$ In line with our result 4 , we find that the amount of sanctions in the previous round does not have a significant effect on the harvest behavior of the participants in the next round. Results from model 3 show that agreeing with the elected leader or implemented rule does not have a significant effect on the harvest behavior of the participants in the second game.

Our fourth model estimates the treatment effects based on the withinsubjects design where we compare individual behavior in the second game with that in the baseline game (open access scenario). In this model we have one dummy for each treatment. For example, 'Representative democracy' is a dummy variable that captures the within-subject effect of elected leadership treatment, and assumes 1 if the participant plays the second game with elected leadership and this game is the second one, and zero if the game is the baseline game. A similar definition can be given to 'Imposed leadership', 'Direct democracy' and 'Imposed rule' in this model. Instead of round fixed effects, we now include session fixed effects to account for unobserved heterogeneity between groups. Thus, the treatment effects are only identified by changes over time within a certain group. The regression results are given in table 2 under model 4 . The results show that

8 The inclusion of lagged variables reduces the sample size. 
participation in the election of a leader through a voting mechanism significantly increases cooperative behavior compared to the baseline scenario without leadership (the negative and significant coefficient of 'Representative democracy'). On the other hand, imposed leadership has a significant (negative) effect on cooperation compared to the baseline scenario (the positive significant coefficient of 'Imposed leadership' in model 4). It is also clear from the regression results that, while endogenous rule formation leads to a significant increase in cooperation (negative and significant coefficient of 'Direct democracy'), the exogenous rule formation treatment significantly impedes cooperation (positive and significant coefficient of 'Imposed rule'). In this model we find that the harvest behavior at the beginning of the baseline game (unconditional cooperation) has a positive effect on the HR in later rounds. Possibly, this effect is stronger in the first 10 rounds and becomes insignificant in the second game as shown by the insignificant coefficient of this variable in model 1.

\subsection{Performance of leaders and followers in the experiment}

In this section we explore the cooperative behavior of leaders in our experiment. Table C10 (online appendix) shows the average HR of leaders and followers disaggregated by group. The first five groups (1-5) are endogenously chosen leaders and the remaining three groups (6-8) are exogenous leaders. One can see that all leaders, except those of groups 5 and 7 , became more cooperative after their appointment in the second game. We recognize that the sample size in our study is small and precludes us from making rigorous analysis on the behavior of leaders, and therefore may limit generalizations from our study. Nevertheless, we think the following results provide interesting insights into the mechanisms behind the leadership treatments. A non-parametric (Mann-Whitney) test shows that there is no statistically significant difference between the average HRs of elected leaders and imposed leaders after they assume the leadership position $(n=8, z=1.64, p=0.1011)$. Similarly, elected leaders and imposed leaders are almost equally likely to comply with rules after they become leaders ( $n=58, z=-0.986, p=0.3242$ ). The same observation can be made by looking at the change in the first round HR in game 1 vs. game 2 . This comparison can be seen as the initial willingness to cooperate, independent of the harvest of the group members. As shown in table C10, only one leader (group 4) increased his HR (from 0 to 0.1 ), which is statistically insignificant $(n=8, z=1.48, p=0.1120)$. The two leaders from groups 5 and 7 who increased the average harvest compared to game 1 did start the second game more cooperatively - although they initially broke the rule of harvesting only two trees. Thus, their intentions were not as strong as those of the other leaders. In reality, of course, we may also experience that heterogeneity among leaders may depend on some unobserved leader characteristics.

Result 5. The fact that leaders become more responsible harvesters seems unrelated to how they are appointed.

We further explore the effect of leadership on the harvest behavior of other group members, disaggregated by the way the leaders come to 
power. Here we see a strong difference in the way a leader is appointed. The HR of other members in the groups with an exogenous leader significantly increases in the second game as compared to their respective HR in the baseline game (Wilcoxon signed-rank test: $n=12, z=1.961, p=0.0499$ ). However, in the case of representative democracy, the HR of other group members significantly decreases in the second game compared to their HR in the baseline game (Wilcoxon signed-rank test: $n=20, z=-2.725, p=$ $0.0064)$. Furthermore, the other members from groups with imposed leadership comply with the regulations in only 36 per cent of the cases in the second game, while their counterparts from groups with elected leaders comply in 58 per cent of the cases. In the online appendix we show the disaggregated HR for each group member. In groups with elected leadership, only three out of 20 participants become less cooperative after the election, while 10 out of 12 participants become less cooperative with randomly selected leaders (see tables C10, C11 and C12 in the online appendix). Thus, the overall increase in cooperation that is observed under representative democracy can be attributed to the behavior of the other group members. This is because participation in the election of a leader may provide legitimacy to the authority of the leader and entices others to cooperate more in the management of the commons.

Result 6. Democratic elections of leaders increase the cooperativeness of the other group members compared to the random appointment of leaders.

\section{Discussion of transmission mechanisms behind the effect of democracy on cooperation}

The perception of procedural justice and self-determination achieved through the democratic procedures is the driving force behind the success of democracy (DeCaro et al., 2015). In our study, the 'security' effect that comes through enforcement was not as strong as in the study of DeCaro et al. (2015). This is probably because social norms among Ethiopian resource users are already very strong and do not require additional enforcement, emphasizing the relative importance of procedural fairness and self-determination which are both fostered by direct and representative democracy.

Random assignments into different treatments prevent, for example, more pro-social participants ending up in a specific treatment. It could, however, still be possible that there is some sort of selection with respect to choosing a sanction or not. While we find that sanctions had no effect on $\mathrm{HR}$, we find that agreeing with a rule does reduce harvest rate. This result further emphasizes that the democratic procedure was more important in our subject pool than the enforcement. One remaining testable mechanism that might drive cooperation is the information effect. Majority voting for rules or leaders enables people to signal their intentions (Piketty, 2000), which may increase a certain behavior. In our study we tested for the information effect by including a variable with the number of votes for the winning rule or candidate. If signaling were driving our results, we would expect higher cooperation, the more people voted for a certain rule or 
leader as that signal would be stronger. In our study, however, the signaling effect was not significant.

There is a growing literature in experimental economics showing higher cooperation under democratically elected institutions compared to imposed institutions (Ostrom et al., 1992; Alm et al., 1999; Tyran and Feld, 2006; Dal Bó et al., 2010; Sutter et al., 2010; Markussen et al., 2014; Kamei et al., 2015; Kube et al., 2015), suggesting that the very existence of the option to select among alternatives (which is the essence of democracy) promotes conformance with regulations and increases cooperation (Sutter et al., 2010). When sanctions are seen as legitimate, they can even alter the preferences for rule compliance (Rodriguez-Sickert et al., 2008).

For leadership, several other explanations may additionally play a role. While our main effect is not due to the behavior of the leader itself, our explanation must account for the more cooperative behavior of the followers. ${ }^{9}$ Again, the legitimacy of elected leadership seems central. Weber (1968) mentions that legitimacy may be derived from legal authority, traditional authority or charismatic authority. In our study region, it seems that all three components may be at play since the voting procedure is legally fair and carried out traditionally in the Oromo culture. Lastly, since actual village leaders were also elected in the experiment, it suggests that both game and real-life procedures are deemed legitimate. Thus, elections may lead to the selection of legitimate leaders that are most likely to represent the groups and enhance the cohesion of the groups, which ultimately promotes cooperation.

\section{Conclusions}

In this study we investigate the role of democracy in leader selection and rule formation on cooperation in the commons dilemma using lab-in-thefield experiments in rural Ethiopia. In general, our results suggest that it is less important to participants whether they directly participate in the choice of a type of rule or in the election of a leader who in turn decides on the type of rule to be implemented. The most important thing, however, is the possibility of being involved in the decision-making process in one way or another. Thus, sanctioning rules and leadership only promote cooperation when they are democratically enacted. Our study therefore confirms that representative democracy leads to more cooperation than appointing leaders (see Luo et al., 2007; Baldassarri and Grossman, 2011; Grossman and Baldassarri, 2012; Grossman, 2014) and direct democracy leads to more cooperation than rule imposition (see Ostrom et al., 1992; Ostrom and Nagendra, 2006; Dal Bó et al., 2010; Sutter et al., 2010). We confirm the existing experimental evidence which is mainly based on public good games carried out with students in the lab, for a non-student

${ }^{9}$ Since random leaders behave similarly to democratic leaders, the treatment differences are brought about by the behavior of the followers. This excludes any explanations regarding demand effects that democratically elected leaders behave more pro-socially since they are more in the focus of the experimenter/followers. 
population, in a contextualized dynamic CPR experiment framed as extraction of forest resources. We believe our study increases the faith in policy measures for resource-related problems in developing countries. However, we find no significant difference between representative democracy and direct democracy in promoting cooperation. This finding may contradict Hamman et al. (2011) who, using lab experiments with university students, found that electoral delegation leads to more cooperation than direct democracy in the provision of public goods. This finding may be surprising, as a representative democracy combines two forms of legitimacy: the institutional procedure and the charismatic leader. Nonetheless, comparisons of our results with Hamman et al. (2011) should be made cautiously for three main reasons. First, there are fundamental differences in the setup of the experiments. They used computer lab experiments with university students while ours used a lab-in-the-field experiment with villagers. Secondly, their experiment is based on a static public good game while our experiment is based on a dynamic CPR game framed around forest resource extraction. Thirdly, in their study, participants are given information about the average performance of other members in the baseline game before they choose their leaders. In our study, however, participants cast their vote in the election for a leader based on their real-life experience.

Generally, our results reveal that groups cooperate more when the procedure is legitimate in a specific cultural context. According to Weber (1968), leaders can gain legitimacy through the institutional procedure by which they come into power or by being a specifically charismatic person. Thus, also a non-legitimate procedure might 'produce' a charismatic leader where resource users develop a sense of obligation to act in a compliant manner. In our small sample of leaders we did not observe that randomly elected leaders became legitimate leaders in our experiment. Instead we found that leadership may have an insignificant (or even sometimes negative) effect on cooperation when it is exogenously imposed. In our context this may be due to two reasons. First, electing leaders is a serious issue in the Oromo culture. In the Oromo Gaada system, leaders are usually elected by the society every eight years through a comparable voting mechanism (Melbaa, 1999). Simply randomly choosing someone may not have legitimacy and may not increase the pro-social behavior of the participants. Secondly, the imposed leadership might be connected to the bad relationship the community members in the study area had with the administration of the forest in the past two regimes: the imperial regime (1930-1974) and the military regime (1974-1991). During the imperial regime the forest was owned by landlords for whom most of the community members were peasants. In the case of the military regime, the forest was owned by the state and protected by guards, which alienated the villagers from the resource on which they substantially depended. Before the implementation of the participatory forest management (or community forest management) in the 1990s, the local community did not have any part in the management of the forest in the study area. Thus, the negative effect of imposed leadership might be due to the distrust the local communities have towards imposed leadership. 


\section{Supplementary material and methods}

To view supplementary material for this article, please visit https://doi. org/10.1017/S1355770X16000322.

\section{References}

Alm, J., G.H. McClelland, and W.D. Schulze (1999), 'Changing the social norm of tax compliance by voting', Kyklos 52(2): 141-171.

Arbak, E. and M. Villeval (2013), 'Endogenous leadership selection and influence', Social Choice and Welfare 3: 635-662.

Baldassarri, D. and G. Grossman (2011), 'Centralized sanctioning and legitimate authority promote cooperation in humans', Proceedings of the National Academy of Sciences of the USA 108(27): 11023-11027.

Bardhan, P. (2000), 'Irrigation and cooperation: an empirical analysis of 48 irrigation communities in South India', Economic Development and Cultural Change 48(4): 847-865.

Bardhan, P. (2002), 'Decentralization of governance and development', Journal of Economic Perspectives 16(4): 185-205.

Becker, G.S. (1968), 'Crime and punishment: an economic approach', Journal of Political Economy 76(2): 169-217.

Bekele, M. and T. Bekele (2005), 'Participatory forest management in Bonga and Chilimo, Ethiopia', an evaluation report, Farm Africa, Addis Ababa.

Cardenas, J.-C., M.A. Janssen, and F. Bousquet (2013) 'Dynamics of rules and resources: three new field experiments on water, forests and fisheries', in J. List and M. Price (eds), Handbook on Experimental Economics and the Environment, Cheltenham: Edward Elgar.

Charness, G., U. Gneezy, and M.A. Kuhn (2012), 'Experimental methods: betweensubject and within-subject design', Journal of Economic Behavior and Organization 81(1): 1-8.

Charnley, S. and M.R. Poe (2007), 'Community forestry in theory and practice: where are we now?', Annual Review of Anthropology 36(1): 301-336.

Dal Bó, P. (2005), 'Cooperation under the shadow of the future: experimental evidence from infinitely repeated games', American Economic Review 95(5): 1591-1604.

Dal Bó, P., A. Foster, and L. Putterman (2010), 'Institutions and behavior: experimental evidence on the effects of democracy', American Economic Review 100(5): 2205-2229.

DeCaro, D.A., M.A. Janssen, and A. Lee (2015), 'Synergistic effects of voting and enforcement on internalized motivation to cooperate in a resource dilemma', Judgment and Decision Making 10(6): 511-537.

Engel, S., S. Pagiola, and S. Wunder (2008), 'Designing payments for environmental services in theory and practice: an overview of the issues', Ecological Economics 65(4): 663-674.

Gatiso, T.T. and T. Wossen (2014), 'Forest dependence and income inequality in rural Ethiopia: evidence from Chilimo-Gaji community forest users', International Journal of Sustainable Development and World Ecology 22(1): 1-11.

Grossman, G. (2014), 'Do selection rules affect leader responsiveness? Evidence from rural Uganda', Quarterly Journal of Political Science 9: 1-44.

Grossman, G. and D. Baldassarri (2012), 'The impact of elections on cooperation: evidence from a lab-in-the-field experiment in Uganda' American Journal of Political Science 56(4): 964-985.

Güth, W., M.V. Levati, M. Sutter, and E. van der Heijden (2007), 'Leading by example with and without exclusion power in voluntary contribution experiments', Journal of Public Economics 91(5-6): 1023-1042. 
Hamman, J.R., F. State, and R.A. Weber (2011), 'An experimental investigation of electoral delegation and the provision of public goods', American Political Science 55(4): 737-751.

Irvin, R.A. and J. Stansbury (2004), 'Citizen participation in decision making: is it worth the effort?', Public Administration Review 64(1): 55-65.

Jack, B.K. and M.P. Recalde (2014), 'Leadership and the voluntary provision of public goods: field evidence from Bolivia', Journal of Public Economics 122: 80-93.

Janssen, M.A., F. Bousquet, J.-C. Cardenas, D. Castillo, and K. Worrapimphong (2013), 'Breaking the elected rules in a field experiment on forestry resources', Ecological Economics 90: 132-139.

Kamei, K., L. Putterman, and J.R. Tyran (2015), 'State or nature? Endogenous formal versus informal sanctions in the voluntary provision of public goods', Experimental Economics 18: 38-65.

Kebebew, Z. (2012), 'Chilimo forest change analysis', Farm Africa, Addis Ababa, [Available at] http://www.farmafrica.org/downloads/chilimo-forest-changeanalysis.pdf.

Kosfeld, M. and D. Rustagi (2015), 'Leader punishment and cooperation in groups: experimental field evidence from commons management in Ethiopia', American Economic Review 105(2): 747-783.

Kube, S., S. Schaube, H. Schildberg-Hörisch, and E. Khachatryan (2015), 'Institution formation and cooperation with heterogeneous agents', European Economic Review 78: 248-268.

Levati, M.V., M. Sutter, and E. van der Heijden (2007), 'Leading by example in a public goods experiment with heterogeneity and incomplete information', Journal of Conflict Resolution 51(5): 793-818.

Luo, R., L. Zhang, J. Huang, and S. Rozelle (2007), 'Elections, fiscal reform and public goods provision in rural China', Journal of Comparative Economics 35(3): 583-611.

Markussen, T., L. Putterman, and J.R. Tyran (2014), 'Self-organization for collective action: an experimental study of voting on sanction regimes', Review of Economic Studies 81(1): 301-324.

Melbaa, G. (1999), Oromia: An Introduction to the History of the Oromo People, Minneapolis, MN: Kirk House.

Ostrom, E. and H. Nagendra (2006), 'Insights on linking forests, trees, and people from the air, on the ground, and in the laboratory', Proceedings of the National Academy of Sciences of the USA 103(51): 19224-19231.

Ostrom, E., J. Walker, and R. Gardner (1992), 'Covenants with and without a sword: self-governance is possible', American Political Science Review 86(2): 404-417.

Piketty, T. (2000), 'Voting as communicating', Review of Economic Studies 67: 169-191.

Pommerehne, W.W. and H. Weck-Hannemann (1996), 'Tax rates, tax administration and income tax evasion in Switzerland', Public Choice 88(1-2): 161-70.

Posner, R.A. (1997), 'Social norms and the law: an economic approach', American Economic Review 87(2): 365-369.

Ramcilovic-Suominen, S. and G. Epstein (2012), 'Towards an analytical framework for forest law compliance', International Forestry Review 14(3): 326-336.

Rivas, M. and M. Sutter (2008), 'The dos and don'ts of leadership in sequential public goods experiments', Working Papers in Economics and Statistics, University of Innsbruck.

Rivas, M.F. and M. Sutter (2011), 'The benefits of voluntary leadership in experimental public goods games', Economics Letters 112(2): 176-178.

Rodriguez-Sickert, C., R.A. Guzmán, and J.-C. Cárdenas (2008), 'Institutions influence preferences: evidence from a common pool resource experiment', Journal of Economic Behavior and Organization 67(1): 215-227. 
Rustagi, D., S. Engel, and M. Kosfeld (2010), 'Conditional cooperation and costly monitoring explain success in forest commons management', Science 330(6006): 961-965.

Sutter, M., S. Haigner, and M.G. Kocher (2010), 'Choosing the carrot or the stick? Endogenous institutional choice in social dilemma situations', Review of Economic Studies 77: 1540-1566.

Tyler, T.R. (1990), Why People Obey the Law, New Haven, CT: Yale University Press.

Tyran, J.-R. and L.P. Feld (2006), 'Achieving compliance when legal sanctions are non-deterrent', Scandinavian Journal of Economics 108(1): 135-156.

Wade, R. (1994), Village Republics: Economic Conditions for Collective Action in South India. San Francisco, CA: ICS Press.

Weber, M. (1968), Economy and Society: Parts I and II, Berkeley, CA: University of California Press. 